\title{
Assessing investment in manual handling risk controls: a scoring system for use in observational studies
}

\author{
J Smedley, J Poole, E Waclawski, A Stevens, J Harrison, P Buckle, D Coggon
}

Occup Environ Med 2005;62:63-65. doi: 10.1136/oem.2003.012237

Most UK hospitals now have manual handling policies, but few studies have assessed their impact. To facilitate such research, a system for ranking the investment in manual handling risk controls was devised and applied to 109 acute hospitals in the UK. High scoring hospitals performed well on all aspects of manual handling risk management. Low scoring hospitals had a manual handling policy and recorded accidents and sickness absence, but had limited resource for expert manpower and equipment.

$\mathrm{D}$ isorders of the back are a costly problem in hospital nurses. ${ }^{1-3}$ In response, UK hospitals have adopted various risk management strategies, including provision of patient handling equipment, training in patient handling techniques, and fast track rehabilitation for symptomatic nurses. The legal framework ${ }^{4}$ that underpins these actions is based on ergonomic theory, observational epidemiology, and clinical opinion, but there is little direct evidence regarding their effectiveness.

We have previously reported a controlled intervention study, in which we tried to assess the impact of an ergonomic programme. ${ }^{5}$ No effect of the intervention was apparent, either on patient handling activities, or on the prevalence of musculoskeletal symptoms. Intervention studies of this sort are difficult to conduct because of the need for substantial and sustained commitment from hospital managers. Also it is not ethical to impose constant conditions in control hospitals.

Main messages

- This new scoring system (Manual Handling Risk Controls in Hospitals, MARCH) assesses the overall framework for risk management, investment in expert manpower, and specific risk controls such as manual handling training and equipment.

- The individual items of the scoring system were weakly related, and no clear clusters or patterns of risk management activity were identified.

- Hospitals that achieved a high total MARCH score invested heavily in expert manpower and performed well in all aspects of manual handling risk management.

- Hospitals that achieved a low total MARCH score invested little resource in expert manpower or patient handling equipment.

- Further research to explore the association of manual handling risk management with outcomes such as sickness absence is needed.
As a consequence, the differential effect of an intervention may be attenuated, and the power of an investigation reduced.

An alternative approach would be to conduct a cross sectional survey of nurses at a sample of hospitals comparing outcomes according to their investment in risk management. Such a study would be most efficient if it focused on hospitals that differed widely in their level of investment. However, it is necessary first to establish how hospitals vary in their practice, and to identify those which lie at extremes of the distribution. Therefore, we carried out a survey of current approaches to risk management for patient handling in a large sample of UK hospitals. A secondary objective was to explore the relation between investment in risk controls and outcomes such as work loss and litigation.

\section{METHODS}

Acute hospitals were approached through the Association of National Health Service Occupational Physicians (ANHOPS). We identified an appropriate contact (key informant) at 122 hospitals. The key informant was defined as the person with the best overview of arrangements for manual handling risk management in the organisation. Where multiple hospitals were governed by one employer with the same risk management system, they were treated as a single unit.

During 2001-02, information was collected from the key informants by a single interviewer (JS), using a structured questionnaire that covered important aspects of risk management (table 1). Informants were sent a copy of the questionnaire in advance and, if not all questions could be answered at the time of initial interview, were contacted on up to two further occasions.

For each aspect of risk management, answers were scored on a three point scale (table 1), and the scores added to give a summary index for each hospital (Manual Handling Risk Controls in Hospitals (MARCH) score). Because the main purpose of the MARCH score was to identify hospitals at the extremes of the distribution for further study, missing values for most component scores were assigned an intermediate value of one. However, where missing data indicated poor performance (for example, inability to identify a lead manager), the score was set at zero.

Spearman's rank correlation coefficients $\left(\mathrm{r}_{\mathrm{s}}\right)$ were derived to assess the pair-wise association between individual components of the summary MARCH score, and we explored the characteristics of hospitals at the extremes of the distribution. We used linear regression techniques to

\section{Policy implications}

- This simple tool could be used to benchmark manual handling risk management policies in hospitals. 
examine the association of MARCH scores with annual rates of sickness absence in nurses, annual rates of ill-health retirement in all employees, and the rate of compensation claims brought by nurses over a three year period.

\section{RESULTS}

Questionnaires were completed by 109 hospitals (89\% of those approached and approximately $50 \%$ of acute hospitals in the UK). Complete information for the summary MARCH score was available for 60 hospitals. One item was missing for 34 hospitals, and 15 hospitals had two or more missing items.
After imputation of missing values, the summary scores were normally distributed, and ranged from 8 to 22 (median 15) out of a maximum possible score of 24 .

Pair-wise correlations between the individual components of the MARCH score were generally weak. The strongest positive correlations were for the proportion of expert manpower allocated to risk assessment with salary allocation for manual handling specialists $\left(\mathrm{r}_{\mathrm{s}}=0.31, \mathrm{p}=0.001\right)$, and with level of training provision $\left(r_{s}=0.30, p=0.001\right)$. Salary for manual handling specialists was also associated with the proportion of clinical wards with lifting equipment $\left(\mathrm{r}_{\mathrm{s}}=0.22\right.$,

Table 1 Aspects of risk management covered in questionnaire and derivation of the MARCH score

\begin{tabular}{|c|c|c|c|c|}
\hline \multirow{2}{*}{\multicolumn{2}{|c|}{ Aspect of risk management }} & \multirow[b]{2}{*}{ Score } & \multicolumn{2}{|c|}{ No. of hospitals } \\
\hline & & & \multirow{2}{*}{$\begin{array}{l}\mathbf{n} \\
13 \\
27\end{array}$} & \multirow{2}{*}{$\begin{array}{l}\%) \\
(12) \\
(25)\end{array}$} \\
\hline 1. & $\begin{array}{l}\text { Defined management responsibility for manual handling } \\
\text { issues at board level }\end{array}$ & $\begin{array}{l}0=\text { none } \\
1=y e s, \text { but with complex or unclear route of communication with } \\
\text { ward manager } \\
2=y e s, \text { and with short and simple route of communication with } \\
\text { ward manager }\end{array}$ & & \\
\hline 2. & Written, trust-wide policy for manual handling & $\begin{array}{l}0=\text { none } \\
1=\text { generic policy only, not ward specific (not applicable or } \\
\text { information missing) } \\
2=\text { generic policy and also ward specific policies }\end{array}$ & $\begin{array}{r}1 \\
59 \\
49\end{array}$ & $\begin{array}{r}(1) \\
(54) \\
(45)\end{array}$ \\
\hline 3. & $\begin{array}{l}\text { Score on health and safety section of risk management } \\
\text { audit in NHS Litigation Authority Controls Assurance } \\
\text { Baseline Assessment 2000* }\end{array}$ & $\begin{array}{l}0=\text { lowest third of distribution } \\
1=\text { middle third of distribution (not applicable or information } \\
\text { missing) } \\
2=\text { highest third of distribution }\end{array}$ & $\begin{array}{l}21 \\
63 \\
25\end{array}$ & $\begin{array}{l}(19) \\
(58) \\
(23)\end{array}$ \\
\hline 4. & $\begin{array}{l}\text { Routine collection of data on sickness absence and } \\
\text { ill-health retirement }\end{array}$ & $\begin{array}{l}0=\text { none } \\
1=\text { data collected routinely on either sickness absence or } \\
\text { ill-health retirement, but not both (or information missing) } \\
2=\text { data collected routinely on both sickness absence and } \\
\text { ill-health retirement }\end{array}$ & $\begin{array}{r}1 \\
51 \\
57\end{array}$ & $\begin{array}{r}(1) \\
(47) \\
(52)\end{array}$ \\
\hline 5. & $\begin{array}{l}\text { Data on manual handling incidents collected routinely } \\
\text { and provided to study team on request }\end{array}$ & $\begin{array}{l}0=\text { not collected } \\
1=\text { collected but not provided (or information missing) } \\
2=\text { collected and provided }\end{array}$ & $\begin{array}{r}2 \\
27 \\
80\end{array}$ & $\begin{array}{r}(2) \\
(25) \\
(73)\end{array}$ \\
\hline 6. & $\begin{array}{l}\text { Salary allocation for manual handling specialist(s) } \\
\text { per } 1000 \text { staff }\end{array}$ & $\begin{array}{l}0=\text { lowest third of distribution } \\
1=\text { middle third of distribution or salary allocated but amount } \\
\text { unknown } \\
2=\text { highest third of distribution }\end{array}$ & $\begin{array}{l}40 \\
39 \\
30\end{array}$ & $\begin{array}{l}(37) \\
(36) \\
(28)\end{array}$ \\
\hline 7. & $\begin{array}{l}\text { Time per } 1000 \text { staff of manual handling specialist(s) } \\
\text { allocated to advising about risks and controls }\end{array}$ & $\begin{array}{l}0=\text { lowest third of distribution } \\
1=\text { middle third of distribution or specialist appointed but time } \\
\text { allocation unknown } \\
2=\text { highest third of distribution }\end{array}$ & $\begin{array}{l}39 \\
40 \\
30\end{array}$ & $\begin{array}{l}(36) \\
(37) \\
(28)\end{array}$ \\
\hline 8. & $\begin{array}{l}\text { Guidelines on referral to occupational health } \\
\text { department for nurses with back problems }\end{array}$ & $\begin{array}{l}0=\text { none } \\
1=\text { guidelines produced, but referral not always within first } \\
\text { four weeks of sickness absence (or information missing) } \\
2=\text { guidelines produced and referral within first four weeks } \\
\text { of sickness absence }\end{array}$ & $\begin{array}{l}15 \\
66 \\
28\end{array}$ & $\begin{array}{l}(14) \\
(61) \\
(26)\end{array}$ \\
\hline 9. & $\begin{array}{l}\text { Rapid access to physiotherapy for nurses with back } \\
\text { problems }\end{array}$ & $\begin{array}{l}0=\text { none } \\
1=\text { available, but waiting time }>2 \text { weeks (or information missing) } \\
2=\text { available and waiting time } \leqslant 2 \text { weeks }\end{array}$ & $\begin{array}{l}25 \\
18 \\
66\end{array}$ & $\begin{array}{l}(23) \\
(17) \\
(61)\end{array}$ \\
\hline 10. & Level of manual handling training & $\begin{array}{l}0=<1 \text { day at baseline } \\
1=\text { other (or information missing) } \\
2=\geqslant 1 \text { day at baseline plus } \geqslant 1 / 2 \text { day refresher at least } \\
\text { once per year }\end{array}$ & $\begin{array}{l}44 \\
24 \\
41\end{array}$ & $\begin{array}{l}(40) \\
(22) \\
(38)\end{array}$ \\
\hline 11. & $\begin{array}{l}\text { Records of attendance for manual handling training } \\
\text { and proportion of nurses with attendance in past year }\end{array}$ & $\begin{array}{l}0=\text { training records kept only at ward level } \\
1=\text { training records kept centrally and attendance rate in } \\
\text { lower half of distribution (or information missing) } \\
2=\text { training records kept centrally and attendance rate } \\
\text { in upper half of distribution }\end{array}$ & $\begin{array}{l}13 \\
64 \\
32\end{array}$ & $\begin{array}{l}(12) \\
(59) \\
(29)\end{array}$ \\
\hline 12. & $\begin{array}{l}\text { Proportion of clinical wards with accessible } \\
\text { liffing equipment }\end{array}$ & $\begin{array}{l}0=\leqslant 80 \% \text { of wards have either hoists or small aids } \\
1=>80 \% \text { of wards have both hoists and small aids, but } \\
\text { some or all are shared with other wards (or information missing) } \\
2=>80 \% \text { of wards have both hoists and small aids for } \\
\text { single ward use }\end{array}$ & $\begin{array}{l}30 \\
43 \\
36\end{array}$ & $\begin{array}{l}(28) \\
(39) \\
(33)\end{array}$ \\
\hline
\end{tabular}


$p=0.02$ ). Rapid access to physiotherapy for nurses with back problems was positively associated with the proportion of wards with accessible lifting equipment $\left(r_{s}=0.24, p=0.01\right)$, collection of data on sickness absence and ill-health retirement $\left(\mathrm{r}_{\mathrm{s}}=0.22, \mathrm{p}=0.02\right)$, and well defined management responsibility at board level $\left(r_{s}=0.21, p=0.03\right)$. These relationships persisted when missing values were excluded rather than being assigned a default value.

Twelve hospitals scored below 12. All of these lowest scoring hospitals had a manual handling policy, and systems for recording manual handling incidents, and sickness absence and/or ill-health retirements. However, investment in manual handling expertise was low. Nine of the 12 were in the lowest third of the distribution for salary resource. Seven hospitals scored zero for equipment provision, and none scored maximally for this item.

At the other extreme, 12 hospitals scored above 18 . These hospitals tended to score highly on most items. Thus, 10 were in the highest third of the distribution of salary allocation for expert advice; all 12 scored maximally for ability to produce clear data on manual handling incidents; 10 scored maximally for equipment provision; and 11 offered nurses access to physiotherapy within two weeks of a back injury. However, even the highest scoring hospitals struggled to maintain training records, only four attaining the maximum for this element.

To explore the sensitivity of the MARCH rankings to missing data we re-ranked the scores, assigning a value of zero to missing data. There were few missing data at the extremes, and the rankings were not altered substantially.

In the regression analyses, there was no significant relation of MARCH score with either sickness absence rate in nurses or the rate of ill-health retirement in all staff. If anything, higher scores were associated with an increased frequency of claims for compensation by nurses (a unit increase in total score was associated with a $10 \%$ increase in the proportion of litigation cases; $\mathrm{p}=0.06$ ). There was no significant relationship between individual item scores and either sickness absence or ill-health retirements. However, there was a strong positive association between the level of training and the proportion of litigation cases brought by nurses (2.5-fold increase in litigation for hospitals that provided at least a day of baseline and half a day of refresher training annually compared with those which provided baseline training of less than half a day; $\mathrm{p}=0.002$ ).

\section{DISCUSSION}

The full descriptive results of the MARCH survey have been reported elsewhere. ${ }^{6}$ The principal aim of this analysis was to identify hospitals for a subsequent investigation comparing the patient handling activities of nurses, and their rates of musculoskeletal symptoms and disability, according to the employer's approach to risk management for manual handling. For this purpose it was not essential that the hospitals should be nationally representative. The coverage of approximately $50 \%$ of potentially eligible hospitals means that our findings, if accurate, should give a reasonable indication of the variation in practice in the UK. However, our data may have tended to overestimate the average investment in manual handling if hospitals with more active programmes were more likely to have occupational medical advisers who were members of ANHOPS and if key informants who were involved in implementing risk controls were more likely to report them favourably.
We took care to consult relevant experts within each hospital, and give them time to seek out information. The informants showed a high level of commitment. Therefore, we believe that the information provided is likely to have been generally reliable. Even so, certain items of information could not be obtained for all hospitals. However, the main findings of the study did not depend critically on the handling of these missing data.

The MARCH score was defined a priori, and encompassed various aspects of risk management for manual handling. Although some of the individual items correlated with each other, such inter-relationships were usually weak. This meant that the ranking of a hospital according to its summary score might be importantly influenced by the choice of elements making up the score and the relative weight given to each. We therefore looked in more detail at the characteristics of hospitals at extremes of the distribution for the MARCH score.

This revealed a clear pattern. At the lower end of the distribution, hospitals had a basic manual handling policy and collected data on sickness absence and/or ill-health retirement, but invested little resource in specialist manpower or equipment. At the other extreme, specialist input was much greater, and most aspects of risk management were well covered. This distinction provides a reasonable basis on which to select hospitals for future, more detailed investigation.

Within the current study, we did explore whether the total MARCH score or the component items were related to sickness absence, ill-health retirement, or compensation claims, but found no evidence of an inverse association. This might be because more intense risk management for patient handling is ineffective, but other possibilities are that the outcomes examined were too crude or that a small effect was missed by chance. It is also conceivable that managers had invested more heavily in controls because of a particular local problem. The further study that we plan will collect data on outcomes that are more specific to the hazards from manual handling in nurses.

\section{Authors' affiliations \\ J Smedley, J Poole, D Coggon, MRC Environmental Epidemiology Unit, University of Southampton, UK \\ E Waclawski, A Stevens, J Harrison, Association of NHS Occupational Physicians Research Committee, UK \\ P Buckle, Robens Centre for Health Ergonomics, European Institute of Health and Medical Sciences, University of Surrey, UK}

Correspondence to: Dr J Smedley, MRC Environmental Epidemiology Unit, Southampton General Hospital, Southampton SO16 6YD, UK; jcs@mrc.soton.ac.uk

\section{Accepted 6 June 2004}

\section{REFERENCES}

1 Smedley J, Egger P, Cooper C, et al. Manual handling activities and risk of low back pain in nurses. Occup Environ Med 1995;52:160-3.

2 Buckle P. Epidemiological aspects of back pain the nursing profession. Int J Nurs Stud 1987;24:319-24.

3 Leighton D, Reilly T. Epidemiological aspects of back pain: the incidence and prevalence of back pain in nurses compared to the general population. Occup Med 1995;45:263-7.

4 Health and Safety Executive. Manual Handling Operations Regulations. London: HMSO, 1992.

5 Smedley J, Trevelyan F, Inskip H, et al. The impact of ergonomic intervention on back pain in nurses. Scand J Work Environ Health 2003;29:117-23.

6 Smedley J, Poole J, Waclawski E, et al. Manual Handling Risk Controls in Hospitals (MARCH) - a cross sectional survey of UK hospitals. Health Services Management Research 2004;17:121-31. 